\title{
Urban Green Development towards Sustainability in Northwest China: Efficiency Assessment, Spatial-Temporal Differentiation Characters, and Influencing Factors
}

\author{
LiJuan Si, ${ }^{1,2}$ JiaLu Wang, ${ }^{2}$ ShuRan Yang, ${ }^{2}$ Ye Yang $\mathbb{D},{ }^{3}$ and Jing Zhang $\mathbb{D}^{2}$ \\ ${ }^{1}$ Institute of Green Finance, Lanzhou University, Lanzhou, China \\ ${ }^{2}$ School of Economics, Lanzhou University, Lanzhou, China \\ ${ }^{3}$ Institute of Finance and Economics, Central University of Finance and Economics, Beijing, China \\ Correspondence should be addressed to Ye Yang; yangye@email.cufe.edu.cn and Jing Zhang; jingzhang15@lzu.edu.cn
}

Received 25 November 2020; Revised 12 January 2021; Accepted 18 February 2021; Published 3 March 2021

Academic Editor: Wei Zhang

Copyright (c) 2021 LiJuan Si et al. This is an open access article distributed under the Creative Commons Attribution License, which permits unrestricted use, distribution, and reproduction in any medium, provided the original work is properly cited.

For achieving the sustainable development goals, green development has been raised to a high position for cities in China. The economic development in Northwest China is slow, the ecological environment is fragile, and the mineral resources are rich. Only through green development can we realize the comprehensive income of regional production development, rich life, and good ecology. This paper measures the green development efficiency of 30 prefecture-level cities in Northwest China by using DEASBM model of unexpected output, explores the differences and causes of green development efficiency from the perspective of time and space through convergence coefficient, coordination matrix, GIS, and other methods, and empirically tests the impact of industrial structure, technological progress, and other driving factors on green development efficiency by using panel Tobit model. The results show that, on the whole, the efficiency of green development in Northwest China is low, path dependence is serious and unbalanced, the coordinated development effect of different regions is weak, and the spillover effect of core urban agglomerations has not been effectively exerted; from the perspective of driving factors, economic development, population density, traffic situation, and education investment can significantly improve the efficiency of urban green development, and the second is that the proportion of industries significantly hinders the improvement of green development efficiency, while the impact of scientific and technological innovation is not significant. Based on the empirical results, this paper believes that the harmonious development of natural environment and economic society can be realized only by improving the coordinated development effect among cities, implementing the optimization and upgrading of industrial structure, introducing excellent talents, and promoting the technological upgrading.

\section{Introduction}

Since the beginning of the 21st century, the ecological environment capacity and resource carrying capacity have gradually become the main factors restricting economic development. A green economy based on traditional industries, coordinated economic and environmental development, and market oriented has become an inevitable choice for China's development strategy. British economist Pearce's "Green Economy Blue Book," published in 1989, first proposed the concept of a green economy. He believed that economic development must not be at the expense of environmental damage. At the same time, the exhaustion of resources was never the cause of economic stagnation, and green development was a breakthrough in resources' environmental constraints, transforming environmental advantages into development advantages, transforming the dynamic mechanism of economic growth, changing the way economic growth is focused, unifying economic growth, social development, and eco-friendliness to achieve highquality economic growth, and the coordination and fairness of society as a whole effective sustainable development. Green development is the era of China's development, and it is a key move in the construction of ecological civilization. 
Since 2012, ecological civilization construction has been fully promoted, and the process of green development has accelerated significantly. Green development, low-carbon development, and cyclic development have become the basic requirements for economic construction. The five concepts of innovation, coordination, greenness, openness, and sharing became the core of development. The implementation of a series of policies provided adjustments for the economic structure and green development which make the northwest region with strong kinetic energy support.

Northwest China has a complex and diverse terrain, a fragile ecological environment, and abundant mineral resources. The environmental pressures and social problems caused by predatory development in the last century have continued to appear in recent years, becoming a major bottleneck restricting development. The five northwestern provinces of China have an area of about $30 \%$ of China's total area and a population of about 130 million. In 2018, the total economic volume was 51.46 billion yuan, accounting for only $5.7 \%$, which is lower than the provinces of Zhejiang and Shandong. At present, China's industrial upgrading is accelerating. The implementation of the "Belt and Road" initiative and the comprehensive management of the Yellow River Basin has provided a platform for the rise of the Northwest region. Therefore, seizing the opportunity to realize green development and improve the quality of economic development are the biggest opportunities of the five Northwest provinces.

This paper takes the main prefecture-level cities in the five Northwestern provinces of China as the main research body, measures its green development efficiency, analyzes its equilibrium characteristics from two aspects of time and space, and combines technical measures such as convergence coefficient, GIS, and coordinated equilibrium matrix to green the city cluster coordinated development which is analyzed. Finally, Tobit regression is used to explore the factors affecting its green development efficiency from economic development, industrial structure, and other aspects. Based on this, it provides the Northwest region with the goal of improving green development efficiency and achieving coordinated economic, social, and ecological development.

\section{Materials and Methods}

2.1. Literature Review of Green Development. With the continuous emergence of resources and environmental issues and the increasing awareness of environmental protection, green economy has gradually become the theme of world development. In terms of functional definition, green development is the second-generation sustainable development concept, and it is an economic, social, and natural system of integrated and coordinated system [1]. The development of the concept of green development is a change in development value. The goal of people-oriented, social progress, respect for nature, and ecological development is the ultimate goal of green development [2]. China's green development is formed on the basis of continuous summarization of traditional economic development and has experienced a dynamic process from elementary to advanced, from simple to complex $[3,4]$. In the 21 st century, if China is to achieve high-quality economic growth and a winwin situation for ecological well-being, it must change its development model and take a green development path to promote a green economy [5]. Therefore, it is particularly important to evaluate the effect of green development from a quantitative perspective.

At present, the research subjects of green development practice evaluation focus on two aspects. On the one hand is to measure the green development of the entire country or key areas. Kunanuntakij, based on the green GDP accounting logic, used the EIO-LCA method to establish Thailand's green GDP model and conducted in-depth research on consumption costs, degradation costs, and defense costs in green GDP [6]. Ezici evaluated the impact of nonrenewable resources and renewable resources on the green development of US manufacturing from the perspectives of ecology and efficiency. From the perspective of input and output [7], Laura evaluated the sustainable development capacity of urban society and economy and tested the impact of economic development and technological innovation on green development [8]. Some scholars use China as the research area and discuss the industrial development level and green development in different regions of Chinese cities from 2005 to 2016. Nonlinear relationship [9] and the impact of environmental regulations on industry and its intermediary effects on green development were studied, through evaluating the effectiveness of green development in other countries combined with the DDF and Durenberger index analysis methods based on relaxation measures, the low-carbon and green development status of the 52 countries along the "Belt and Road" in 1995-2016 was explored, and socio-economic factors affecting the growth of low-carbon and green TFP in the region were analyzed by panel regression [10]. Zhang studied the impact of environmental regulation policy on the transfer of the whole industry and five pollution intensive industries and discussed the impact of local government environmental regulation on green development [11]. However, macroresearch finds it difficult to avoid the endogenous nature of the data, and the analysis of influencing factors is often superficial. Therefore, the research on green development focusing on hot economic areas or special background areas is the main research interest at present. Tian takes the Yangtze River Economic Belt for measurement, and based on the greening measurement index and the extreme value entropy method, the greening index of the Yangtze River Delta urban agglomeration is calculated systematically and the influencing factors of the greening development of the Yangtze River Delta urban agglomeration based on the panel Tobit model are calculated [12, 13], Some scholars have made the green development of China's impoverished areas and constructed an ecological index system [14] and explored the role of industrial structure changes in underdeveloped areas to promote green development efficiency $[15,16]$. Si analyzed the impact of environmental regulations in the Yellow River basin on green technology innovation [17]. Generally speaking, the green development effect of 
China's regions is U-shaped, and there are differences in the East, the middle, and the west, but there is a convergence trend.

On the other hand, research on green development focuses on measurement methods and indicator systems for green development; currently existing research mainly uses DEA and indicator system to construct two types of methods. The input-output data envelopment analysis (DEA) is used more frequently. Farrell [18] used the inputoutput method for the first time to measure the output efficiency of multiple inputs, but the existence of unintended outputs limited the further use of the model. In 1983, Pittman [19] added unintended output to the model, and the model gradually developed into a hot model for studying efficiency issues. With the continuous improvement of this model by scholars, its analysis and application boundaries for green development issues continue to expand. On the basis of combining the concept and connotation of green development, Zhou used DEA-SBM-undesirable model and other methods to measure and characterize the spatiotemporal characteristics of green development efficiency in Chinese cities from 2005 to 2015 [20, 21]. Lin used a nonradial direction distance function to construct and evaluate green economic efficiency indicators for cities at the prefecture level and above in the Super-DEA framework and further empirically studied the impact of economic agglomeration on green economic efficiency [22]. Measuring the green development index by building an indicator system and adopting an empowering method is another method which combines data and theoretical foundations better and can comprehensively evaluate the effect of green development $[23,24]$.

2.2. Theoretical Basis. The concept of green development is formed in the criticism of the traditional development path. With the development of human society, the pressure on resources and the environment has gradually increased, and the phenomenon of "humanity's impact in many aspects has exceeded the environmental tolerance" has appeared. The imbalance between resources, environment, and economic and social development has become a challenge for all mankind and even threatens the survival of mankind. Therefore, scholars first reflect on the relationship between humans and the environment and explore human production and development models. The concept of green environmental protection has begun to emerge. From green production to green consumption, the embryonic form of sustainable development has been formed, and its obvious characteristic is that it is separated from the economic system and, instead, focuses on environmental issues. With the development of society, the theory of green economy and sustainable development has been gradually improved. British scholar Pierce first put forward the concept of "green economy" and regarded resource protection and environmental conservation as important aspects of economic development. Ecological issues should not be ignored for economic growth. Economic development should follow the principles of sustainability, eco-friendliness, and rational allocation of resources, focusing on how economic and social development affects the environment, solving pollution problems, and achieving overall development [25]. Since the 21st century, the theoretical system of green development has become more mature and has been continuously promoted in international organizations. In 2011, the United Nations Environment Program's "Green Economy Report" was released, stating that green development "means better use of natural resources and sustainable growth: a more effective and fairer economic model." As the largest developing country in the world, with the rapid development of economy, the continuous emergence of resource and environmental problems, and the increasing awareness of environmental protection, green economy has gradually become the theme of national development. The harmony and unity of man and nature is the realization of green development. Basically, from the perspective of function definition, green development is the second generation of sustainable development concept, which is the systematic, integrated, and coordinated development of economy, society, and nature. The proposal of green development concept is the transformation of development value, putting people first and society. The value goal of progress, respect for nature, and ecological development is the ultimate goal of green development.

2.3. Assessment Method. This paper uses the DEA-SBM model based on undesired output to measure the green development efficiency of cities in Northwest China. Based on this, the green development coordination of major urban agglomerations in Northwest China is measured through a convergence coefficient. Tobit regression is used to analyze the driving effects of the driving factors of green development efficiency.

\subsubsection{Green Development Efficiency Measurement.} Measuring the green development efficiency of a city based on a data model is an important method in academia at present. Its advantage is that it can measure efficiency through input and output, thereby avoiding the impact of price indexes and production functions. The measurement results are more objective. The current commonly used development efficiency methods include data envelope analysis and stochastic frontier analysis. Data envelopment analysis takes the effectiveness of different resource allocations as the efficiency of economic development and incorporates environmental factors, resource factors, and factor endowments into the research system to improve the rationality and effectiveness of the calculation. After years of continuous development, the data envelopment analysis method has continuous improvement. Tone [26] introduces nonradial relaxation variables into the DEA data envelope analysis model so that nonzero relaxation factors are included in the efficiency calculation, which solves the radial problem of the traditional DEA model and improves the accuracy of the calculation. Unexpected output is introduced into the nonradial DEA-SBM model, thus forming a more comprehensive and efficient measure of green development 
efficiency. Fukuyama [27], on the basis of Tone, proposed a more operable DDF model based on relaxation measures, which further improves the application range of the data envelope analysis method. Based on the research purpose of this paper, the DEA-SBM method based on undesired output was selected to measure the urban green development efficiency in Northwest China.

This article considers each city as a production unit, and its different input volume decisions and its output determine the efficiency of green development. The optimal inputoutput situation of each period of output is constructed by multiple production units, assuming that there are $n$ production decision-making units, whose factors are input factors, expected output factors, and undesired output factors and are represented by different vector matrices when the returns to scale are unchanged. $X \in R^{m}$, $X=\left[X_{1}, X_{2} \ldots X_{n}\right] \in R^{m * n} ; Y^{g} \in R^{s^{1}}, Y^{g}=\left[Y^{g^{1}}, Y^{g^{2}}, \ldots\right.$, $\left.Y^{g^{n}}\right] \in R^{s^{1} * n} ; Y^{b} \in R^{s^{2}}, Y^{b}=\left[Y^{b^{1}}, Y^{b^{2}}, \ldots, Y^{b^{n}}\right] \in R^{s^{2} * n}$, assume $X>0, Y^{g}>0$, and $Y^{b}>0$. The set of production possibilities is $P=\left\{\left(x, y^{g}, y^{b}\right) \mid x \geq X \alpha, y^{b} \geq Y^{b} \alpha, y^{g} \geq Y \alpha^{g}\right\}$, $\alpha \in R^{n}$ is the intensity vector. According to the above definition, a DEA-SBM model based on undesired output is obtained:

$$
\rho^{*}=\min \frac{1-(1 / m) \sum_{i=1}^{m} s_{i} / s_{i 0}}{1+\left(1 /\left(s_{1}+s_{2}\right)\right)\left(\sum_{r=1}^{s_{1}} s_{r}^{g} / y_{r 0}^{g}+\sum_{r=1}^{s_{2}} s_{r}^{b} / y_{r 0}^{b}\right)} .
$$

$x_{0}=X \alpha+s^{-}, y_{0}^{g}=Y^{g} \alpha-s^{g}$, and $y_{0}^{b}=Y^{b} \alpha+s^{b}, s^{-} \geq 0$, $s^{g} \geq 0, s^{b} \geq 0$, and $\alpha \geq 0$. The optimal solution is $\left(\alpha^{*}, s^{-*}, s^{g *}, s^{b *}\right)$. In the presence of unexpected output, only $\rho^{*}=1, s^{g *}=0$, and $s^{b *}=0$ and production units are efficient.

2.4. Regional Difference Measure. Urban agglomerations are important engines for regional development. Four major urban agglomerations were formed in the Northwest during the 13th Five-Year Plan period, including the Guanzhong plain urban agglomeration (Xi an, Tongchuan, Baoji, Xianyang, Weinan, and Yan'an), the Ningxia urban agglomeration (Yinchuan and Shizuishan), Lanxi urban agglomeration (Lanzhou, Jinchang, and Xining), and the northern slope urban agglomeration (Urumqi and Karamay); the coordinated green development of the urban agglomeration will form a strong driving force for the entire region. To measure the degree of green coordinated development, the convergence coefficient is used to measure the change in the dispersion of the green development efficiency of important urban agglomerations in Northwest China. When the convergence coefficient gradually decreases over time, it means that the degree of dispersion is gradually reduced, and the coordination efficiency of green development in urban agglomerations is gradually improved [28]. The calculation formula is

$$
\begin{aligned}
\sigma_{1} & =\sqrt{\frac{1}{S-1} \sum_{1}^{s}}\left(y_{i t}-y_{t}^{-}\right) *\left(y_{i t}-y_{t}^{-}\right), y_{t}^{-} \\
& =\frac{1}{S} * \sum_{1}^{s} y_{i t}, \quad i=1,2, \ldots, S, t=1,2, \ldots, T .
\end{aligned}
$$

In the formula, $y_{i t}$ is the green development efficiency of each prefecture-level city in year $t$ and $y_{i}^{-}$is the average green development efficiency of all regions in year $t$; if $\sigma_{t}>\sigma_{t+1}$, it means it is convergent.

At the same time, in order to further explain the comprehensive development of the coordination and efficiency of the urban agglomeration during the measurement period, this article measures the coordination within the urban agglomeration by the coordination coefficient [29]:

$$
\begin{aligned}
\phi & =-\sqrt{\frac{1}{S} \sum_{1}^{s}}\left(y_{i t}-y_{t}^{-}\right) *\left(y_{i t}-y_{t}^{-}\right)+\varepsilon \\
i & =1,2, \ldots, S, t=1,2, \ldots, T,
\end{aligned}
$$

where $y_{i t}$ is the green development efficiency of each prefecture-level city in year $t, y_{i}^{-}$is the average green development efficiency of all regions in year $t$, and $\varepsilon$ is the equilibrium constant, which is taken as 0.5 .

2.4.1. Green Development Performance-Driven Measure. Because the value of green development efficiency ranges from $0-1$ and the degree of green development in the northwest region is low, there is a low possibility of being completely effective or superefficient. Therefore, this paper uses the panel Tobit model to empirically test the urban development potential influencing factors, with a view to make useful policy recommendations for improving the efficiency of green development in Northwest China [30]. This paper takes the green development efficiency as the explanatory variable and uses the level of economic development, industrial structure, technological innovation, population density, transportation status, and education investment as explanatory variables to construct the following model:

$$
\begin{aligned}
\mathrm{T} \rho^{*}= & \beta_{0}+\beta_{1 *} \ln G D P_{i t}+\beta_{2} * \ln \operatorname{Indu} \operatorname{str}+\beta_{3} * \ln T e c h \\
& +\beta_{4} * \ln D \text { speo }+\beta_{5} * \ln \text { Traffic }+\beta_{6} * \ln E d u c a t i o n+e_{i t} .
\end{aligned}
$$

In order to reduce the effect of sample data heteroscedasticity, the study variables are treated as logarithms, $\beta_{0}$ is the intercept term, $\beta_{1}-\beta_{6}$ is the coefficient to be evaluated for image factors, and $e_{i t}$ is the random interference term. 


\subsection{Index Selection}

2.5.1. The Input-Output Indexes. According to the theory of neoclassical economics, it can also be extended to technology input and resource input. Capital investment is an important driving force for green development. This article uses the amount of investment in fixed assets at the end of the year as capital input; labor input is an important basis for promoting the greening process. Because data on labor time and labor efficiency are difficult to obtain, this paper uses the number of employees which represents labor input; resource input is the endowment foundation of a region. Good resource input can effectively promote development. Considering the availability of data, this article uses the area of the built-up area to represent the input of urban land resources, uses annual water supply to indicate the input of urban water resources, and uses the annual power supply to represent the input of urban power resources.

Expected output variable: the objective indicator of economic development in a region is GDP. Therefore, this article uses urban GDP to indicate the expected output. Unexpected output: the most important factor affecting green development in the development of a region is wastewater, harmful gas, and harmful solid waste, so this article uses wastewater emissions, sulfur dioxide emissions, and smoke dust emissions to represent the unintended output of urban green development.

2.5.2. The Driving Factors' Indexes. Based on the measurement of the urban green development efficiency in the Northwest region, the most important driving factors for the preliminary judgment of urban green development include economic development level, industrial structure, scientific, technological innovation capabilities, population density, traffic conditions, and education investment. Clarifying the impact of different driving factors is important for deeper analysis, so the following variables are selected for measurement in this article.

Economic development level: this article uses GDP per capita to measure the level of urban economic development. The Kuznets curve (EKC) theory shows that environmental pollution presents an "inverted U-shaped" curve that first increases and then decreases with the continuous growth of the economy. The economic growth of cities on the left side of the curve will continue to negatively affect the environment, but with the further implementation of national policies, the further implementation of green industry and green energy-related policies by local governments will greatly reduce the impact on the environment while promoting economic development. With the further prosperity of the economy, more funds will be invested in environmental governance and the degree of green development in cities may increase.

Industrial structure, this article uses the proportion of the secondary industry to measure the city's industrial structure. Due to historical reasons and dependence on the path of economic development, the secondary industry in Northwest China accounts for a relatively high proportion.
At the same time, the discharge of waste related to the secondary industry greatly affects the construction of ecological civilization, continuous advancement of industrialization, and production of wastewater, waste gas, and solid waste. The rapid increase will have a negative impact on green efficiency, but with the continuous implementation of the green development concept and the continuous upgrading of the industry, the emissions of the three wastes are reduced, and the green development efficiency may gradually increase.

Scientific and technological innovation capabilities and the effects of innovation results can effectively spill over to highly polluting industries such as industry and construction, innovate pollution control methods, promote the upgrading of industrial structure and the construction of ecological civilization, and improve the efficiency of green development. Because there are no precise statistics on innovation efficiency in different regions and innovation requires a large amount of capital investment, this article uses urban science and technology expenditure to measure innovation capacity.

Population density and human resources are the most basic of many resources. There are enough talents for the future. Human resources in the Northwest are relatively lacking. There is a mismatch of resources, environment, economy, and human capital. An important factor is that an increase in population density can increase urban vitality and promote the improvement of green development efficiency. Similarly, an excessively high population density will bring urban problems such as serious urban pollution and traffic congestion and will also adversely affect green development.

Traffic conditions are the basis of regional industrial development. Good traffic conditions will reduce industrial energy consumption and improve the efficiency of green development to a certain extent. Due to the lack of relevant statistical data of roads at different levels in various cities, this article uses road area to represent urban traffic conditions.

Education investment: this article takes education expenditure in local fiscal investment as a measure of education investment. Continuous investment in education will lead to the continuous enrichment of educational resources, thereby outputting more high-quality talents, and highquality talents have a higher level of self-literacy and knowledge and are willing to pay more for green products Capital is more willing to invest in green development industries, so education investment may have a positive effect on green development, but there is a certain time lag between education investment and high-quality talent output.

2.6. Data and Study Areas. The relevant data in this article comes from the "China City Statistical Yearbook," "China Energy Statistical Yearbook," provincial and municipal statistical yearbooks, and the National Energy Administration and National Bureau of Statistics. For the missing data, this paper uses expectation-maximum to estimation. 
Combining the availability of data and considering different categories of government authority and administrative levels, this article selects 30 prefecture-level cities in the Northwest region as the research object (Table 1).

\section{Results}

\subsection{Current Situation of Green Development in Various Regions}

3.1.1. Status Quo of Input Factors. Resource inputs and nonresource inputs are an important driving force for green development and a key factor affecting the efficiency of green development. Higher inputs can only achieve reasonable efficiency if they produce outputs that match them (Figure 1). From the perspective of nonresource input, fixed assets in the Northwest have shown a steady upward trend. In 2007, fixed asset investment was 613.678 billion yuan. In 2017, fixed asset investment increased by 3.925267 trillion yuan, an increase of 6.4 times. The urban labor supply of Northwest China showed a trend of rising first and then falling. In 2014, the urban labor supply peaked at 9.721 million. From the perspective of resource input, the supply of land resources, power resources, and water resources has been slowly increasing, but the growth rate is lower than the input of fixed assets.

3.1.2. Status Quo of Output Factors. Expected output and undesired output are important results of regional green development (Figure 2). From the perspective of expected output, the total growth rate of Northwest China's total GDP in the eleven years from 2007 to 2017 reached 7\%. In the Northwest, sulfur dioxide emissions, smoke and dust emissions, and industrial wastewater emissions generally showed a declining trend. In some years, the emissions of three wastes increased, which inhibited the improvement of the efficiency of green development. At the same time, the three wastes are $10.9 \%, 1.5 \%$ and $4.6 \%$. The reduction efficiency of the unexpected output is generally lower than the increase efficiency of the expected output, which may lead to the lower efficiency of the input-output.

3.2. Time Analysis of Green Development Efficiency in Different Regions. The analysis of the original data through MATLAB 2018a yields the green development efficiency scores of prefecture-level cities in the Northwest region. Due to the lack of unexpected output data of Zhongwei City in 2018, the data is interpolated through SPSS. So, exclude this score and finally get the data results of this article (Table 2).

\subsubsection{The Unbalanced Characteristics of Green Development} Efficiency. The overall efficiency of green development in Northwest China is relatively low, but there is an obvious upward trend in 2007-2017. The average green development efficiency of Shaanxi Province is higher, with an average annual value of more than 0.5 and an increase of $24.8 \%$ in 2007-2017, with the best green development efficiency.
From 2007 to 2017, the growth rate of green efficiency in Ningxia reached $31.2 \%$, with the fastest growth.

From the provincial level, Shaanxi Province has the highest green development efficiency, while Gansu Province, Ningxia Autonomous Region, Xinjiang, and Qinghai Province have lower green development efficiency. From the perspective of the internal development of Shaanxi Province, the green development efficiency of all cities in Shaanxi Province is relatively balanced. The green development efficiency of Xi'an, Xianyang, Weinan, and Baoji is in the first echelon. The internal development of Gansu Province is quite different. The green development efficiency of Lanzhou is in the first echelon, but the green development efficiency of Jinchang, Jiuquan, Zhangye, and other cities is poor. The green development efficiency of Yinchuan Guyuan and Zhongwei is gradually increasing. In general, the efficiency of urban green development in Northwest China is characterized by low level, large gap, imbalance, and rapid growth.

3.2.2. Path Dependence and Matthew Effect in Green Development Efficiency. From the perspective of the green development efficiency of prefecture-level cities, since the green development efficiency of Shaanxi Province is generally higher than that of other regions, the change of the top five cities which include Xi'an, Xianyang, Weinan, Ankang, and Baoji is relatively small. And, the last five cities are mainly heavy industry cities with poor natural conditions, so this paper selects the middle 6-20 prefecture-level cities' green development efficiency to reflect the change of the cities in Northwest China (Table 3). Generally speaking, the sixth to eighth places of green development efficiency have little change, and they are all cities of Shaanxi Province. Lanzhou city of Gansu Province has high green development efficiency, ranking 10 to 11 , with little change, ranking 12 to 20 cities with more intense change, and the ranking of Shizuishan, Jiayuguan, Yinchuan, Karamay, and other cities has changed greatly from 2007 to 2017. The high-efficiency and low-efficiency areas of urban green development in Northwest China have changed a little, while the mediumefficiency cities have changed a lot, and the path of green development efficiency of prefecture-level cities depends heavily, which forms Matthew effect. The high-efficiency development areas rely on the development advantages to form scale advantages and then promote the further green development of the areas. The low-efficiency areas have high pollution and high energy consumption industries. A large number of the existence of green development leads to low efficiency, which brings more negative effects, but more restrictions on the improvement of green development efficiency.

\subsubsection{Provincial Capital Cities Will Play an Important Role.} Intercept the data of 2007, 2012, and 2017 and compare it with the average green development efficiency of that year to explore the change of green development efficiency of prefecture-level cities in Northwest China over time (Figure 3). From the perspective of trend, the green development 
TABle 1: Data source cities.

\begin{tabular}{lc}
\hline Province & Cities \\
\hline Shanxi & Xian, Tongchuan, Baoji, Xianyang, Weinan, Yan an, Hanzhong, Yulin, Ankang, and Shangluo \\
Gansu & Lanzhou, Jiayuguan, Jinchang, Baiyin, Tianshui, Wuwei, Zhangye, Pingliang, Jiuquan, Qingyang, Dingxi, and Longnan \\
Qinghai & Xi ning \\
Ningxia & Yinchuan, Shizuishan, Wuzhong, Guyuan, and Zhongwei \\
Xinjiang & Urumqi and Karamay \\
\hline
\end{tabular}

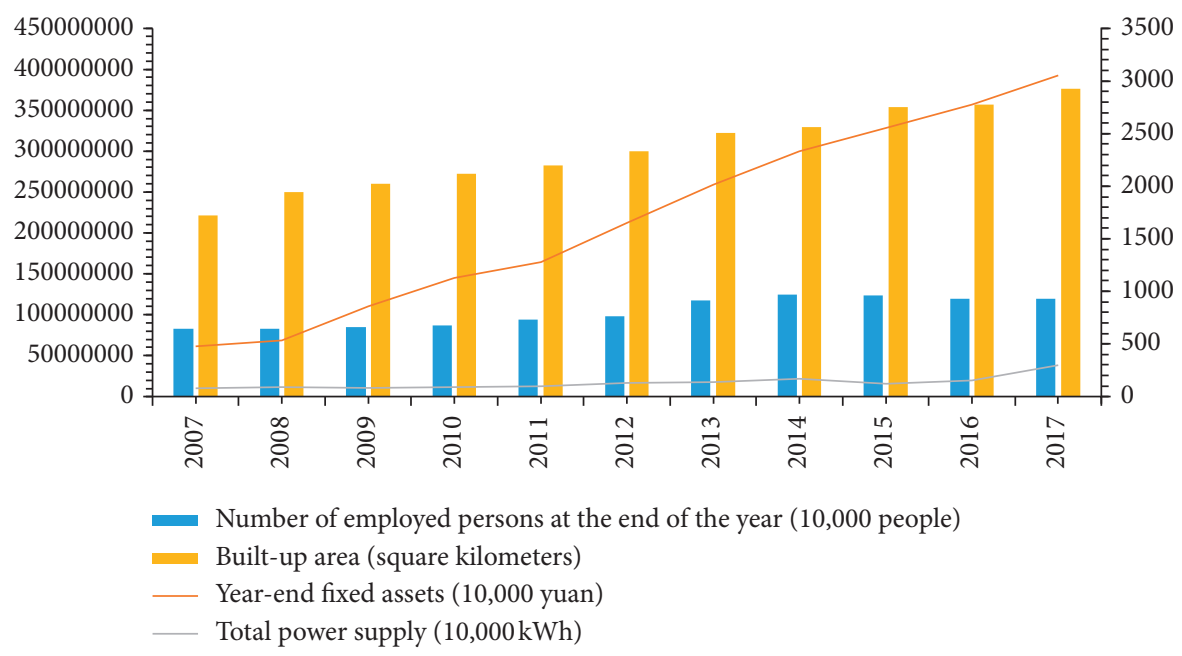

Figure 1: Input factors of prefecture-level cities in Northwest China.

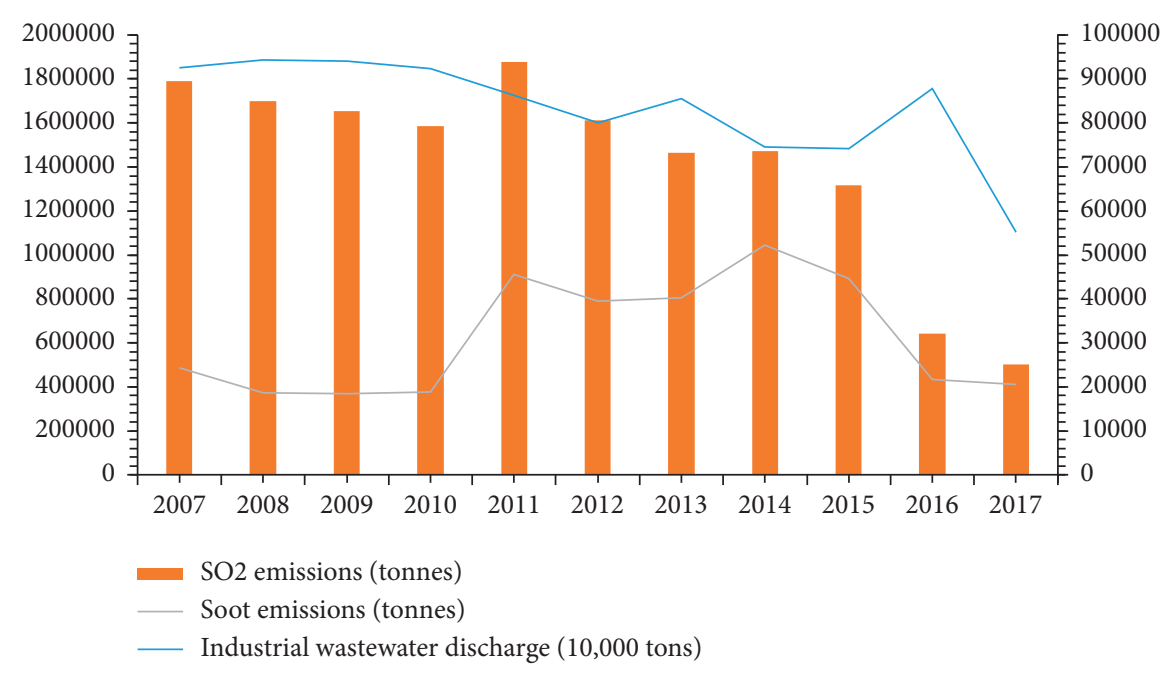

FIGURE 2: Unexpected output in prefecture-level cities.

efficiency of prefecture-level cities in Northwest China is developing well. In 2007, the green development efficiency of ten prefecture-level cities exceeded the average, accounting for only $33 \%$ of all prefecture-level cities. In 2012, 12 prefecture-level cities exceeded the average. Lanzhou and Longnan were new cities. In 2017, 14 prefecture-level cities exceeded the average, accounting for $47 \%$ of all cities, $14 \%$ higher than 2007, Including Xining, Yinchuan, Urumqi, and other provincial capitals. The efficiency of green development has been improved. It can be clearly seen from the green development efficiency of cities in Northwest China that the green development efficiency of provincial capital cities has increased rapidly and become the locomotive of green development efficiency of Northwest China. It is a feasible path to achieve the improvement of green development efficiency of all cities in the province through the promotion of provincial capital cities.

3.3. Spatial Analysis of Green Development Efficiency in Different Regions. In 2007, the overall urban pattern in Northwest China situation was "strong in the East and 
TABLe 2: Green development efficiency of prefecture-level cities in Northwest China.

\begin{tabular}{|c|c|c|c|c|c|c|c|c|c|c|c|}
\hline & 2007 & 2008 & 2009 & 2010 & 2011 & 2012 & 2013 & 2014 & 2015 & 2016 & 2017 \\
\hline $\mathrm{Xi}$ an & 0.553 & 0.592 & 0.619 & 0.503 & 0.511 & 0.503 & 0.526 & 0.541 & 0.587 & 0.623 & 0.692 \\
\hline Tongchuan & 0.434 & 0.436 & 0.416 & 0.494 & 0.501 & 0.424 & 0.417 & 0.512 & 0.552 & 0.528 & 0.576 \\
\hline Baoji & 0.488 & 0.461 & 0.455 & 0.524 & 0.549 & 0.538 & 0.571 & 0.580 & 0.579 & 0.593 & 0.624 \\
\hline Xianyang & 0.532 & 0.528 & 0.549 & 0.559 & 0.582 & 0.593 & 0.601 & 0.638 & 0.668 & 0.673 & 0.685 \\
\hline Weinan & 0.539 & 0.546 & 0.572 & 0.567 & 0.578 & 0.552 & 0.537 & 0.584 & 0.618 & 0.611 & 0.623 \\
\hline Yan an & 0.504 & 0.513 & 0.538 & 0.569 & 0.566 & 0.596 & 0.579 & 0.591 & 0.610 & 0.615 & 0.605 \\
\hline Hanzhong & 0.547 & 0.533 & 0.546 & 0.523 & 0.571 & 0.549 & 0.557 & 0.576 & 0.582 & 0.607 & 0.591 \\
\hline Yuling & 0.408 & 0.432 & 0.486 & 0.454 & 0.488 & 0.523 & 0.544 & 0.529 & 0.564 & 0.579 & 0.587 \\
\hline Ankang & 0.511 & 0.519 & 0.533 & 0.527 & 0.526 & 0.531 & 0.557 & 0.545 & 0.579 & 0.592 & 0.583 \\
\hline Shangluo & 0.485 & 0.499 & 0.482 & 0.533 & 0.514 & 0.541 & 0.546 & 0.559 & 0.533 & 0.586 & 0.551 \\
\hline Shaanxi & 0.508 & 0.513 & 0.525 & 0.536 & 0.548 & 0.534 & 0.539 & 0.574 & 0.602 & 0.607 & 0.634 \\
\hline Lanzhou & 0.312 & 0.323 & 0.349 & 0.391 & 0.426 & 0.422 & 0.456 & 0.476 & 0.503 & 0.512 & 0.572 \\
\hline Jiayuguan & 0.216 & 0.228 & 0.269 & 0.242 & 0.258 & 0.282 & 0.277 & 0.284 & 0.292 & 0.328 & 0.319 \\
\hline Jinchang & 0.167 & 0.159 & 0.156 & 0.178 & 0.184 & 0.179 & 0.178 & 0.198 & 0.195 & 0.203 & 0.214 \\
\hline Baiyin & 0.177 & 0.195 & 0.183 & 0.186 & 0.215 & 0.209 & 0.219 & 0.215 & 0.214 & 0.223 & 0.206 \\
\hline Tianshui & 0.264 & 0.253 & 0.264 & 0.288 & 0.291 & 0.288 & 0.315 & 0.321 & 0.317 & 0.322 & 0.338 \\
\hline Wuwei & 0.168 & 0.112 & 0.138 & 0.179 & 0.155 & 0.225 & 0.213 & 0.231 & 0.235 & 0.267 & 0.228 \\
\hline Zhangye & 0.174 & 0.129 & 0.147 & 0.182 & 0.177 & 0.182 & 0.218 & 0.227 & 0.253 & 0.247 & 0.244 \\
\hline Pingliang & 0.228 & 0.216 & 0.218 & 0.212 & 0.223 & 0.252 & 0.286 & 0.277 & 0.301 & 0.338 & 0.311 \\
\hline Jiuquan & 0.183 & 0.187 & 0.152 & 0.168 & 0.207 & 0.211 & 0.233 & 0.228 & 0.213 & 0.235 & 0.241 \\
\hline Qingyang & 0.237 & 0.216 & 0.253 & 0.213 & 0.241 & 0.232 & 0.244 & 0.235 & 0.254 & 0.274 & 0.282 \\
\hline Dingxi & 0.196 & 0.198 & 0.215 & 0.218 & 0.236 & 0.244 & 0.241 & 0.231 & 0.208 & 0.217 & 0.204 \\
\hline Longnan & 0.262 & 0.273 & 0.308 & 0.322 & 0.343 & 0.372 & 0.351 & 0.382 & 0.426 & 0.428 & 0.431 \\
\hline Gansu & 0.215 & 0.207 & 0.221 & 0.232 & 0.246 & 0.258 & 0.269 & 0.275 & 0.284 & 0.299 & 0.299 \\
\hline Xining & 0.252 & 0.279 & 0.348 & 0.265 & 0.292 & 0.273 & 0.295 & 0.329 & 0.368 & 0.339 & 0.444 \\
\hline Qinhai & 0.252 & 0.279 & 0.348 & 0.265 & 0.292 & 0.273 & 0.295 & 0.329 & 0.368 & 0.339 & 0.444 \\
\hline Yinchuan & 0.258 & 0.262 & 0.312 & 0.344 & 0.333 & 0.342 & 0.331 & 0.286 & 0.339 & 0.356 & 0.392 \\
\hline Shizuishan & 0.241 & 0.289 & 0.242 & 0.192 & 0.199 & 0.189 & 0.219 & 0.303 & 0.262 & 0.257 & 0.263 \\
\hline Wuzhong & 0.262 & 0.276 & 0.229 & 0.200 & 0.249 & 0.272 & 0.280 & 0.317 & 0.308 & 0.303 & 0.314 \\
\hline Guyuan & 0.297 & 0.293 & 0.379 & 0.362 & 0.344 & 0.246 & 0.346 & 0.390 & 0.474 & 0.447 & 0.331 \\
\hline Zhongwei & 0.281 & 0.273 & 0.283 & 0.248 & 0.251 & 0.258 & 0.256 & 0.322 & 0.292 & 0.266 & \\
\hline Ningxia & 0.25 & 0.276 & 0.277 & 0.268 & 0.266 & 0.2655 & 0.275 & 0.295 & 0.300 & 0.307 & 0.328 \\
\hline Urumqi, & 0.297 & 0.264 & 0.281 & 0.273 & 0.285 & 0.271 & 0.298 & 0.317 & 0.313 & 0.325 & 0.340 \\
\hline Karamay & 0.285 & 0.287 & 0.291 & 0.297 & 0.314 & 0.308 & 0.315 & 0.357 & 0.420 & 0.454 & 0.435 \\
\hline Xinjiang & 0.291 & 0.276 & 0.286 & 0.285 & 0.299 & 0.29 & 0.306 & 0.337 & 0.367 & 0.389 & 0.387 \\
\hline
\end{tabular}

weak in the west." Except for some prefecture-level cities in Shaanxi Province, the green development efficiency of other prefecture-level cities in the northwest was similar, and the overall level was relatively low (Figure 4). At the same time, the green development efficiency of cities in the south central part of Shaanxi Province was significantly higher than that in the north of Shaanxi such as Yulin and In 2012, the overall trend of green development efficiency in Northwest China did not change significantly (Figure 5). The development efficiency in eastern is still much higher than that in western. In 2012, the gap of green development efficiency in Western Shaanxi Province narrowed, especially in northern cities. At the same time, there are obvious differences in the green development efficiency among the cities in Gansu Province, Ningxia autonomous and Xinjiang autonomous. The green development efficiency of the provincial capital city circle headed by Lanzhou, Yinchuan, Xining, and Urumqi is much higher than that of other prefecture-level cities. At the same time, affected by the industrial transfer and the construction of Guanzhong City Cluster, the green development efficiency of Tianshui and other cities in the eastern part of Gansu province is gradually compared with that of Guanzhong Urban Agglomeration convergence; in 2017, the difference of green development efficiency of prefecture-level cities in Northwest China further expanded, Shaanxi Province formed a high-efficiency area centered on Xi an and Xianyang, and the gap between the green development efficiency of capital cities in Gansu Province and Ningxia Autonomous Region and other prefecture-level cities further widened (Figure 6). From the perspective of local cities, the green development efficiency of northern prefecture-level cities in Shaanxi Province is faster than that of central and southern cities, and the gap between the green development efficiency of prefecture-level cities in Shaanxi Province is narrowed, especially the green development efficiency of northern cities is significantly improved.

In general, the green development efficiency of prefecture-level cities in Northwest China shows a trend of rapid concentration from relative balance to provincial capital cities. Under the stimulation of a series of policies, the improvement rate of green development efficiency of provincial capital cities is far higher than that of other prefecture-level cities. In addition, Guanzhong City cluster led 


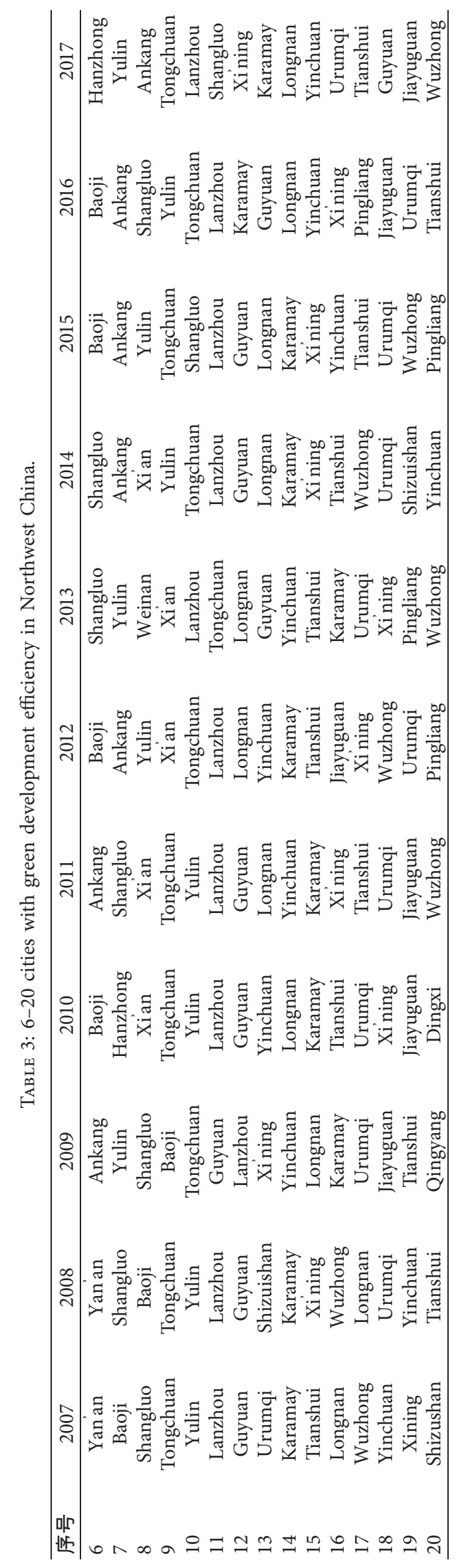




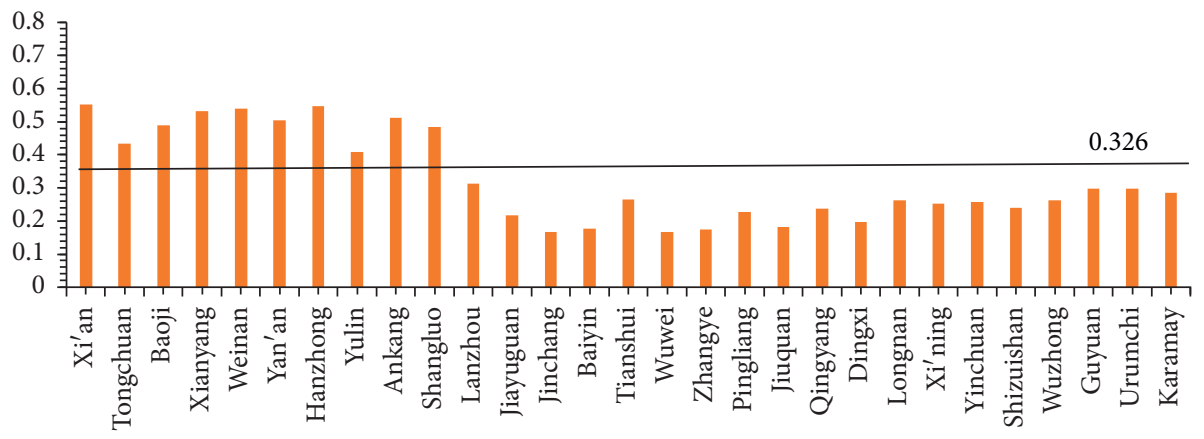

2007
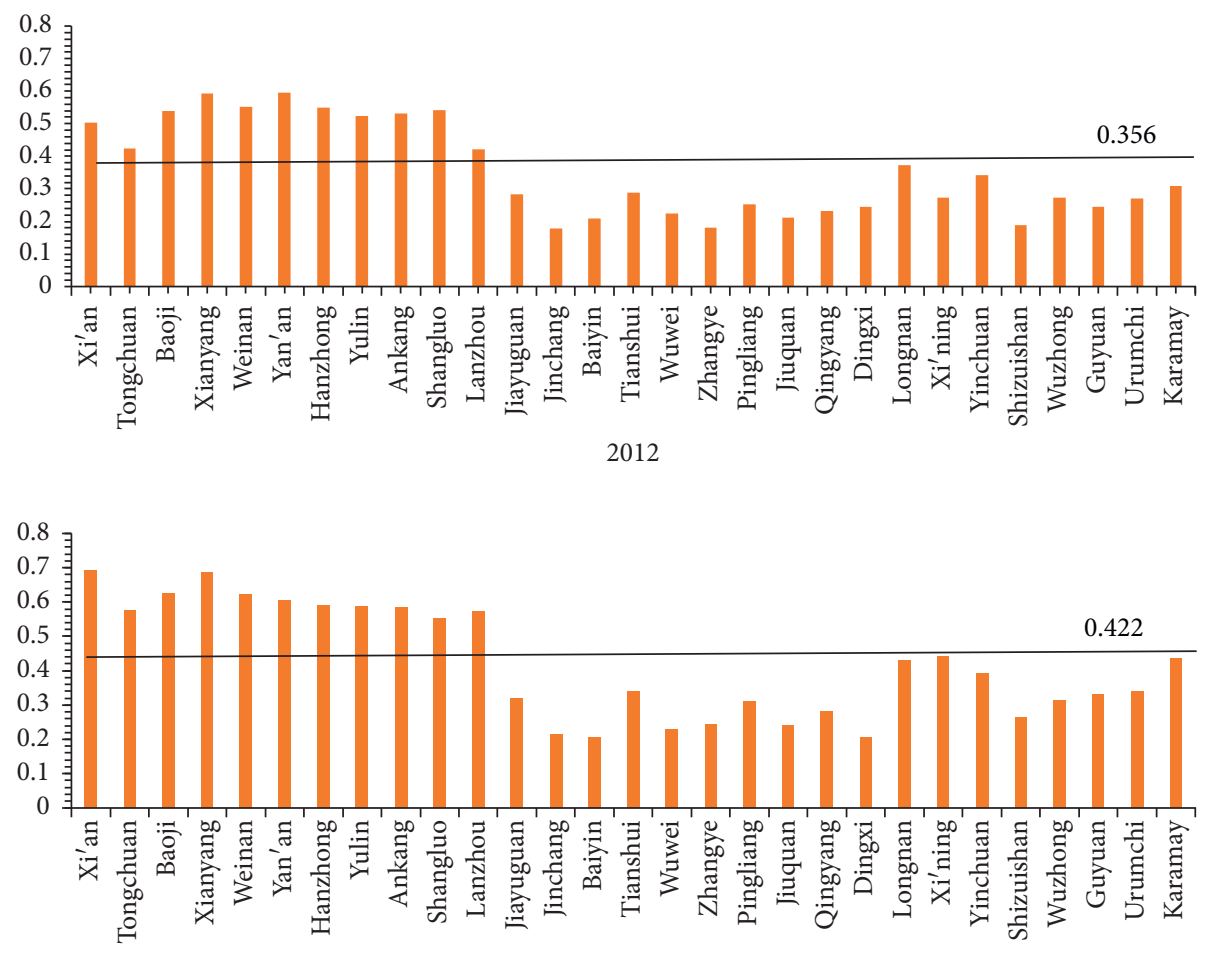

2017

Figure 3: Green development efficiency of prefecture-level cities in Northwest China in 2007, 2012, and 2017.

by Xi'an has become the highest green development efficiency in Northwest China.

\section{Discussion}

4.1. Analysis of Convergence and Coordination of Green Development Efficiency. In Northwest China, there are four urban agglomerations centered on Xi'an (and Tongchuan, Baoji, Xianyang, Weinan, and Yan'an), Lanzhou (and Xining and Jinchang), Yinchuan (and Shizuishan), and Urumqi (and Karamay), which are Guanzhong urban Agglomerations, Lanxi urban agglomerations, Yanhuang urban agglomerations, and Tianshanbeipo urban agglomerations (Figure 7). Through the above spatial analysis, we can clearly see that the provincial capital city is the core area of green development efficiency. At the same time, the city cluster led by the provincial capital city has a high degree of industrial agglomeration and close economic and social ties. The green development of the city cluster will certainly drive and improve the green development efficiency of the whole region. The convergence index is used to measure the difference degree of green development efficiency in urban agglomerations, and the coordination and efficiency coordinate chart is used to measure the coordination and efficiency relationship of green development efficiency in urban agglomerations.

According to the average value of green development efficiency of urban agglomerations in Northwest China (Figure 8), the overall trend is fluctuating and rising. The green development efficiency of Guanzhong urban agglomerations is far ahead of other urban agglomerations, and the convergence index of Guanzhong urban agglomerations shows a stable trend, indicating that the internal gap of green development efficiency of Guanzhong urban 


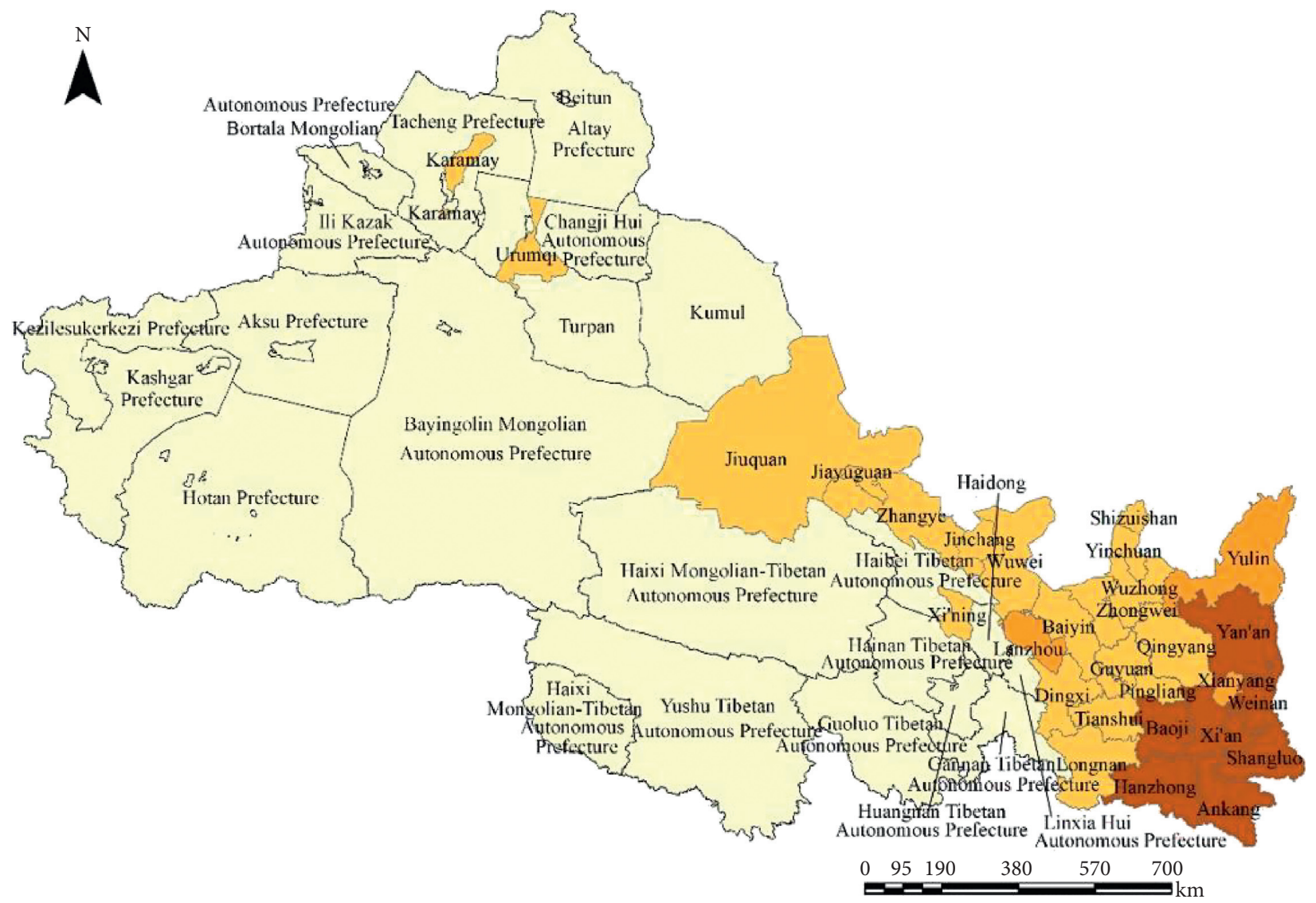

Green development efficiency

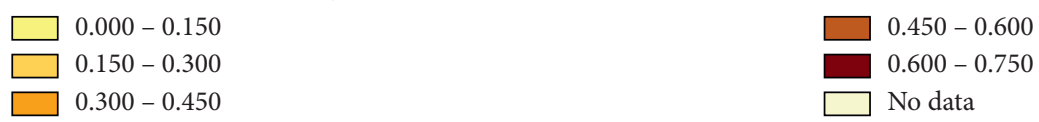

FIgURE 4: 2007 green development efficiency spatial map of prefecture-level cities in Northwest China.

agglomerations has not changed greatly in recent years. During the average green development of Lanxi urban agglomerations in 2007, the efficiency is the lowest among the urban agglomerations in Northwest China, but with the change of time, the average green development efficiency of Lanxi urban agglomerations ranked second in the Northwest China in 2017, and the convergence index of Lanxi urban agglomerations showed a divergent trend, which was $149 \%$ higher than that in 2007, with a significant gap in the efficiency of green development within the urban agglomerations; the convergence coefficient of Ningxia urban agglomerations along the Yellow River showed a fluctuating trend. During the period of 2012-2014, the gap in the efficiency of green development within urban agglomerations gradually narrowed, but gradually expanded after 2014; the convergence index of urban agglomerations on the northern slope of Tianshan Mountain remained stable from 2007 to 2013, but the divergence trend was obvious after 2013, and the efficiency gap within urban agglomerations gradually expanded. After 2014, the Northwest provinces began to gradually expand and strengthen the provincial capital cities. The concentration of many resources has led to a significant increase in the green development efficiency of the provincial capital cities compared with the ordinary low-level cities, and the green development efficiency within each city cluster has obvious characteristics of divergence.

Take the coordination and efficiency values of urban agglomeration in Northwest China during 2007-2017 which are represented in the coordinate system (Figure 9). On the whole, the efficiency value of urban agglomerations in Northwest China has increased well, but the coordination is still at a medium level. It can be seen from the figure that the urban agglomerations in Northwest China are in the middle coordination degree and middle efficiency value range with more coordination and efficiency, and there are few years in the middle coordination, low-efficiency value and middle coordination, and high-efficiency value range. From the perspective of development trend, the urban agglomerations in Northwest China show an obvious momentum of development towards the middle coordination and high-efficiency value (Figure 10). 


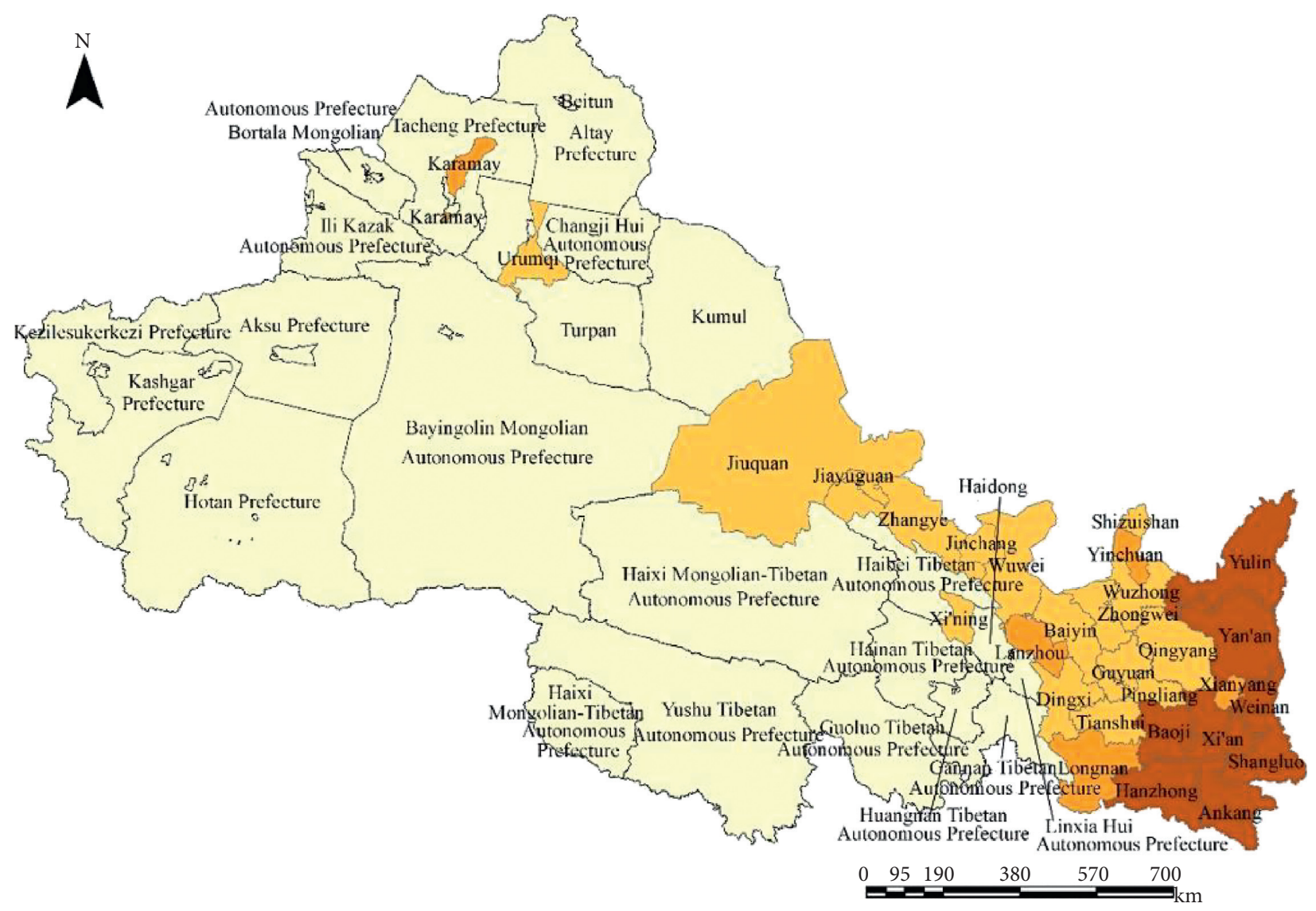

Green development efficiency
$0.000-0.150$
$0.150-0.300$
$0.300-0.450$
$\square 0.450-0.600$

FIGURE 5: 2012 green development efficiency spatial map of prefecture-level cities in Northwest China.

4.2. Analysis of Driving Factors of Green Development Efficiency. The results of green development efficiency measurement of the northwest prefecture-level cities by SBM undesirable model show that there is an overall loss of efficiency in the northwest prefecture-level cities, and there is no case where the efficiency is more than $100 \%$ but expressed as 1. Therefore, the panel Tobit regression of random effects is applicable to the data characteristics of this paper (Table 4).

The economic development level of Northwest China has a positive impact on the green development efficiency at a significant level of $10 \%$, with an impact coefficient of 0.023 . It shows that the relationship between economic development and environmental pollution of prefecture-level cities in Northwest China has reached the right side of "Kuznets Curve." The continuous development of economy promotes the improvement of people's living standards, thus promoting the transformation of their demand relationship. The green consciousness is gradually awakened and the green consumption concept is gradually rooted in the hearts of the people. With the further deepening of the national green development policy, the continuous implementation of relevant provincial and municipal policies, the sustainable development of green economy, the expansion of green market, and the reduction of environmental pollution, the coordination of economy, ecology, and society has been further enhanced, and the efficiency of green development has been continuously improved.

The economic structure has a negative impact on the green development efficiency at a significant level of $1 \%$, with an impact coefficient of -0.034 . Northwest China is rich in mineral resources, which has good conditions for the development of secondary industry. Therefore, it has formed the industrial structure dominated by the secondary industry. At the same time, due to the slow development of Northwest China, the development of green industry, the cultivation of emerging industry, and the adjustment of industrial structure have not been completed. The secondary industry is still dominated by mining, chemical industry, and other raw material processing industries, which is high. The characteristics of pollution, high energy consumption, and high emission are outstanding, which have a relatively bad impact on the environment and seriously inhibit the improvement of green development efficiency. What cannot be ignored is that, 


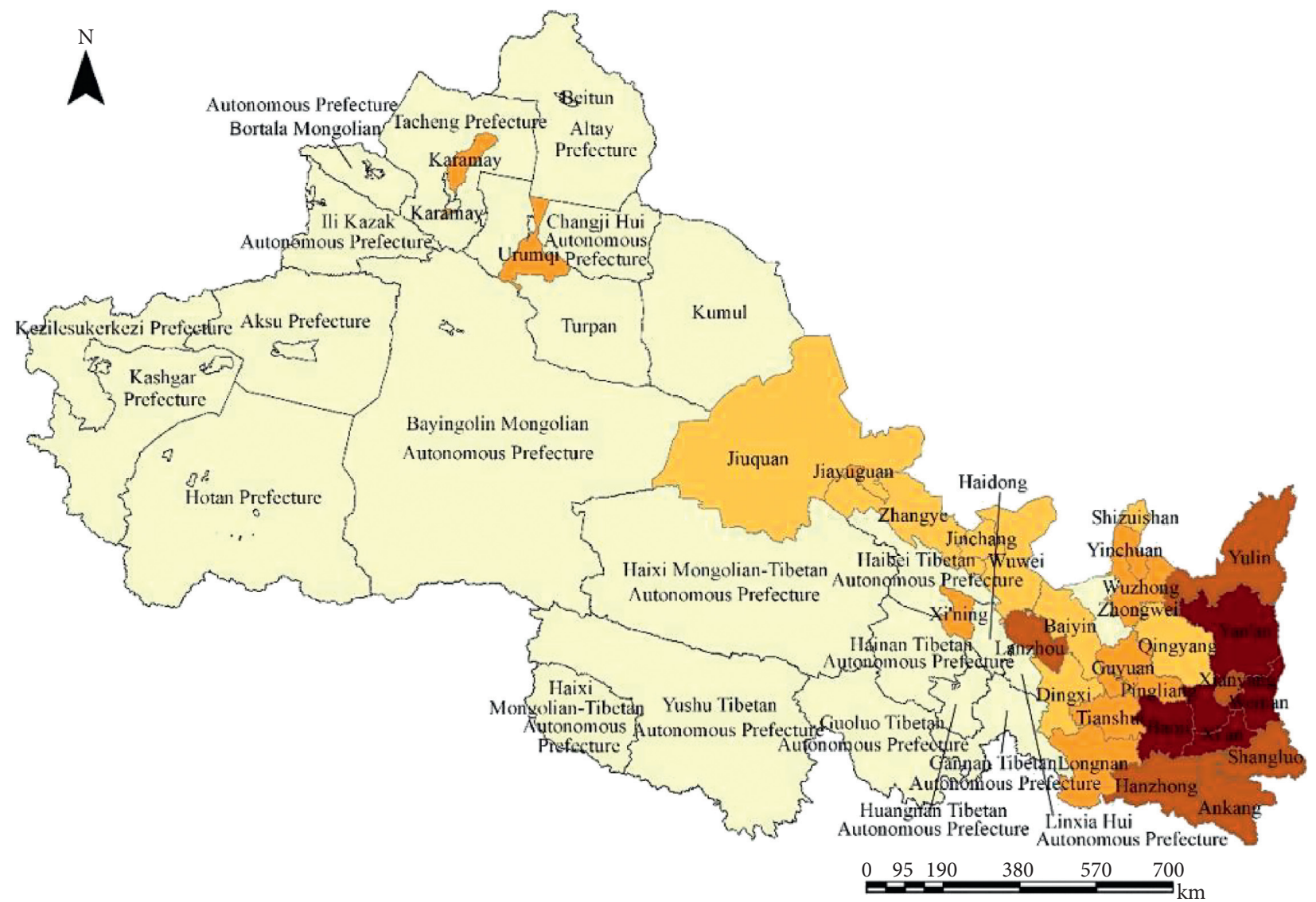

Green development efficiency

$\begin{array}{ll}\square 0.000-0.150 & \square 0.450-0.600 \\ \square 0.150-0.300 & \square 0.600-0.750 \\ \square 0.300-0.450 & \square \text { No data }\end{array}$

FIgURE 6: 2017 green development efficiency spatial map of prefecture-level cities in Northwest China.

as the pillar industry of most cities in Northwest China and the important source industry of government tax revenue, the process of adjusting the structure and changing the mode of the secondary industry must be accelerated. Only when the green of the secondary industry is realized can the green development in Northwest China go on the fast lane and realize the real sustainable development, green development, and harmonious development.

The impact of technological innovation on the green development level of cities in Northwest China is not significant, and cities in Northwest China fail to make full use of the progress of science and technology to promote green development. Northwest China is the lowland of China's higher education. There is only one 985 Engineering University in four provinces except Shaanxi Province. It has the characteristics of low education level and low stock of excellent talents. At the same time, due to the limitations of natural conditions and economic development in Northwest China, the contradiction between the introduction of excellent talents and excellent technology companies is also acute. The lack of higher education resources and the difficulty of introducing technical talents make it difficult for Northwest
China which has been trapped in a cycle in which the ability of scientific and technological transformation is difficult to improve. However, the progress of technology is the indispensable power to realize green development. Good technology development and transformation can improve the comprehensive utilization rate of resources, and it is the most effective way to improve the green development efficiency of the second industry in Northwest China. Therefore, how to improve the scientific and technological innovation ability of Northwest China has become the key to solve the problem of green development in Northwest China.

Traffic and education investment have a positive impact on the efficiency of urban green development in Northwest China under the condition of $1 \%$, the impact coefficient of traffic is 0.063 , and the impact level of education investment is 0.086 . As the infrastructure of urban development, traffic conditions can improve the efficiency of urban value creation in unit time. Good and efficient traffic conditions can connect different regions, which is conducive to capital flow, technology exchange, and talent flow. It is an important basic condition to solve the problem of poor technological innovation ability and slow industrial structure adjustment 


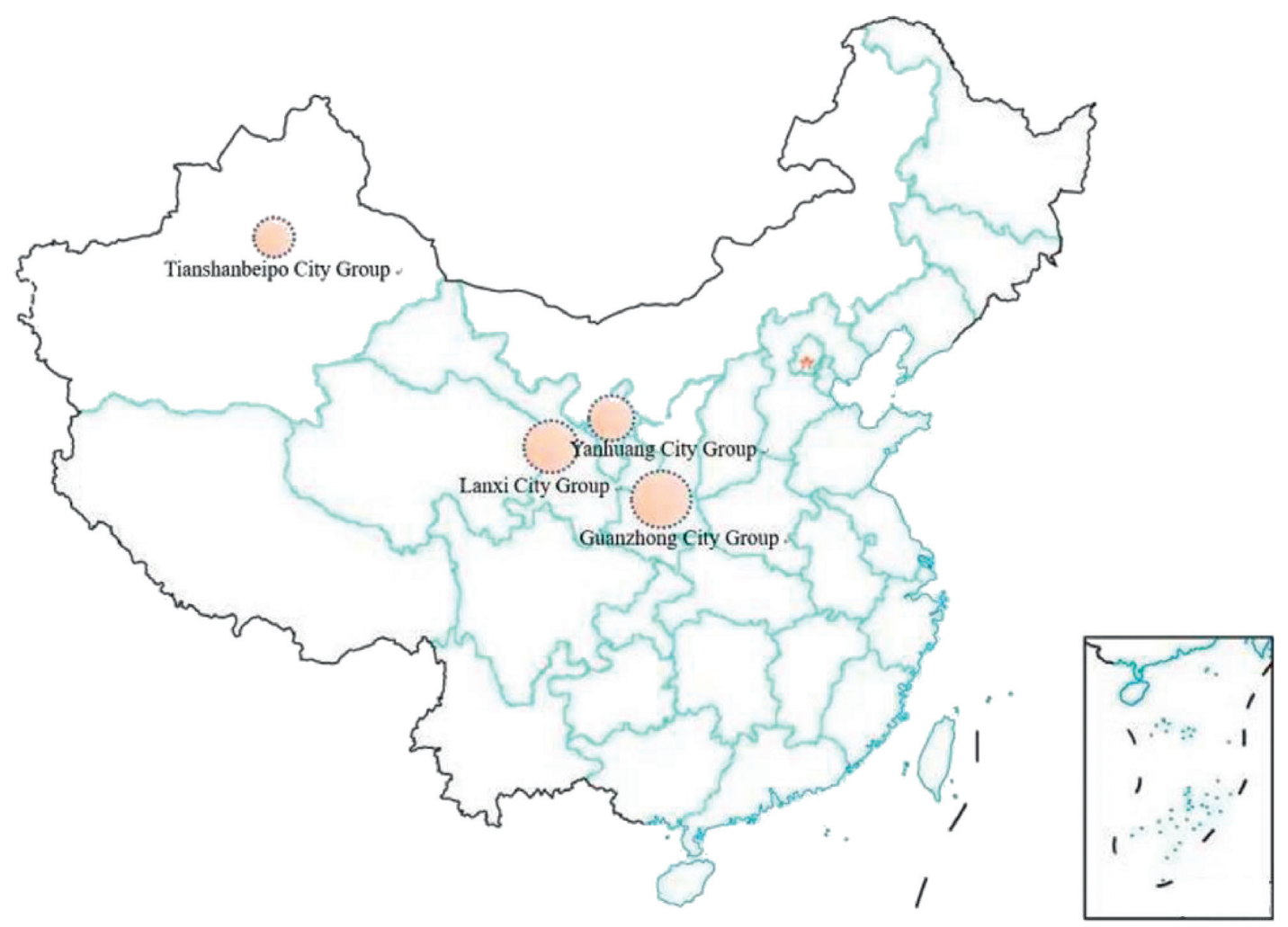

FIgURE 7: Location of urban agglomerations in Northwest China.

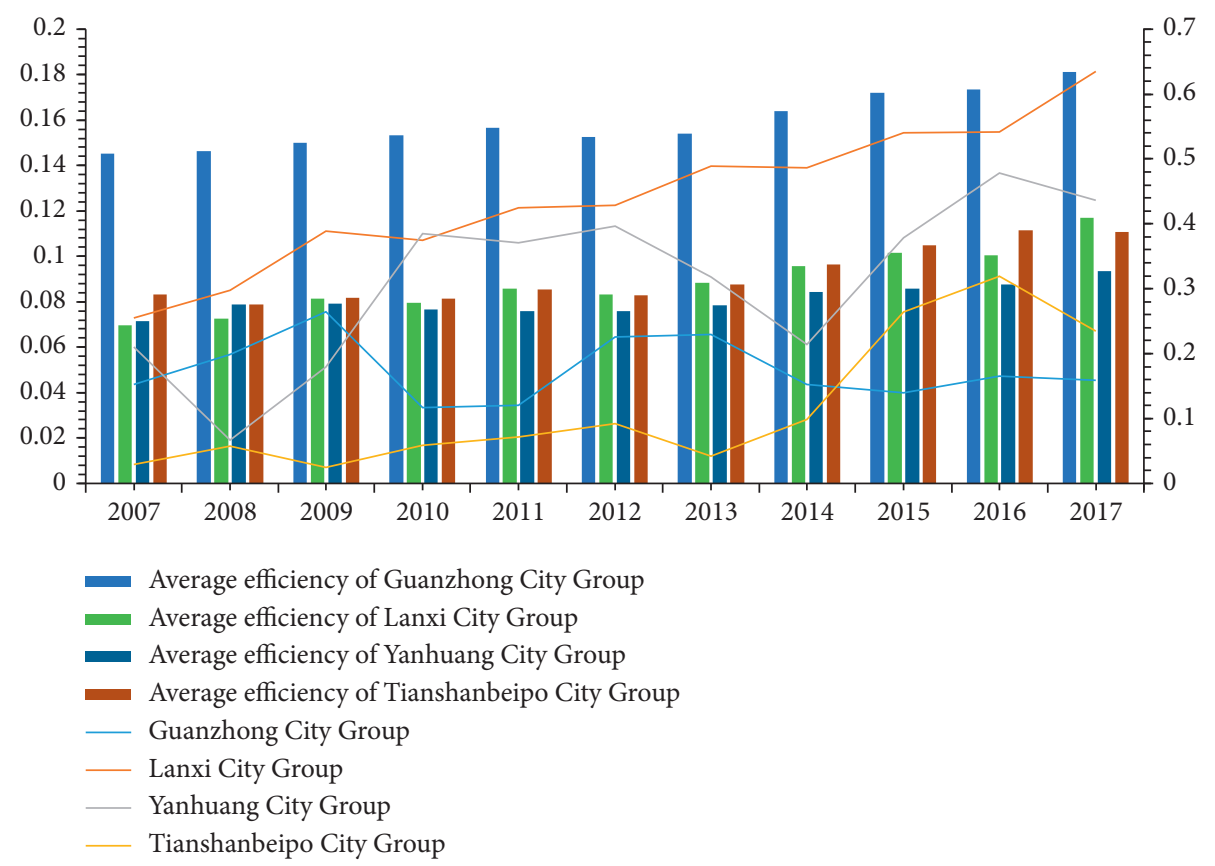

FIGURE 8: Average green development efficiency and convergence coefficient of northwest urban agglomeration, $2007-2017$.

in Northwest China. It is an important engine to increase the endogenous power of urban green development in Northwest China. Education is the future of the development of a region. Good investment in education will improve the quality of the population. A large number of undergraduate and graduate students have made an important foreshadowing for the future introduction of talents in Northwest China. It is an important human resource reserve for the realization of green sustainable development in Northwest China. 


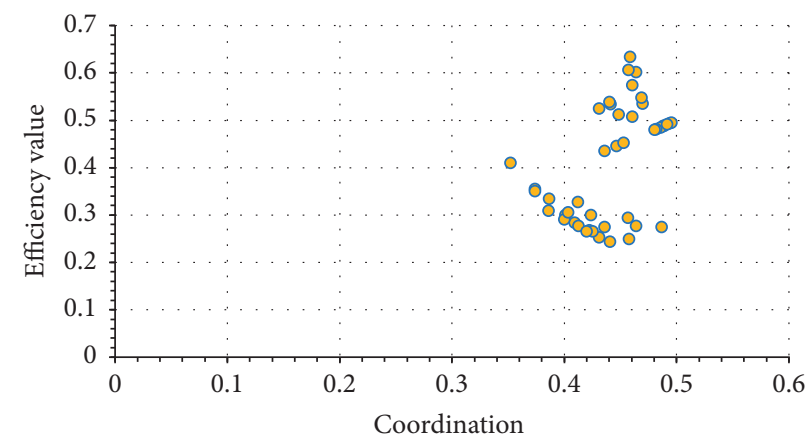

FIgURE 9: Coordination and efficiency matrix of urban agglomerations in Northwest China.

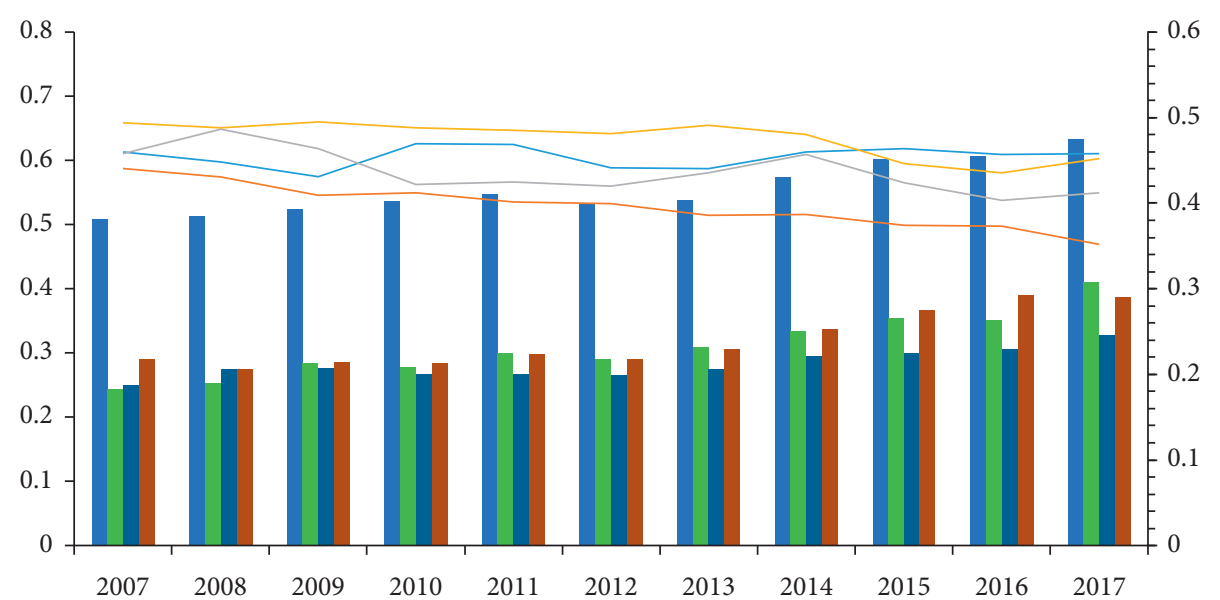

\footnotetext{
Average efficiency of Guanzhong urban agglomeration

Average efficiency of Lanxi urban agglomeration

- Average efficiency of Yanhuang urban agglomeration

Average efficiency of Tianshanbeipo urban agglomeration

- The coordination of Guanzhong City Group

_ The coordination of Lanxi City Group

_ The coordination of Yanhuang City Group

The coordination of Tianshanbeipo City Group
}

FIgURE 10: Efficiency and coordination of green development of urban agglomerations in Northwest China, $2007-2017$.

TABLE 4: Tobit regression results.

\begin{tabular}{lcccc}
\hline T $\rho^{*}$ & Coefficient & Standard deviation & $T$ Test & $P$ \\
\hline Per GDP & 0.023 & 0.013 & 1.85 & -4.14 \\
Industr & -0.034 & 0.008 & 0.22 & 0.065 \\
Tech & 0.002 & 0.011 & 3.95 & 0.028 \\
Dspeo & 0.096 & 0.024 & 7.48 & $P<0.01$ \\
Traffic & 0.063 & 0.012 & 7.16 & $P<0.01$ \\
Education & 0.086 & 0.139 & $P<0.01$ \\
\hline
\end{tabular}

Population density has a positive effect on the urban green development of Northwest China at a significant level of $1 \%$, with an impact coefficient of 0.096 . According to Williamson's hypothesis, the impact of population enrichment on economic development is inverted U-shaped. Population agglomeration in the early stage of economic development brings human capital and other resources, which effectively promotes economic development. However, when the population is over concentrated, the cost of living pollution and traffic jams will offset its advantages, so as to green development has a negative impact. Obviously, population agglomeration in Northwest China is still on the left side of the curve, and effective population agglomeration has a strong role in promoting green development. 
TABLE 5: Tobit regression of urban agglomerations.

\begin{tabular}{|c|c|c|c|c|c|c|c|c|}
\hline \multirow[t]{2}{*}{$\mathrm{T} \rho^{*}$} & \multicolumn{2}{|c|}{$\begin{array}{l}\text { Guanzhong urban } \\
\text { agglomeration }\end{array}$} & \multicolumn{2}{|c|}{$\begin{array}{l}\text { Lanxi urban } \\
\text { agglomeration }\end{array}$} & \multicolumn{2}{|c|}{$\begin{array}{l}\text { Yanhuang urban } \\
\text { agglomeration }\end{array}$} & \multicolumn{2}{|c|}{$\begin{array}{c}\text { Tianshanbeipo urban } \\
\text { agglomeration }\end{array}$} \\
\hline & Coefficient & $P$ & Coefficient & $P$ & Coefficient & $P$ & Coefficient & $P$ \\
\hline Per GDP & 0.034 & 0.021 & 0.051 & 0.000 & 0.102 & 0.015 & -0.027 & 0.260 \\
\hline Industr & -0.076 & 0.000 & -0.092 & 0.000 & -0.309 & 0.001 & -0.192 & 0.000 \\
\hline Tech & -0.001 & 0.911 & 0.154 & 0.004 & 0.039 & 0.138 & -0.073 & 0.000 \\
\hline Dspeo & -0.007 & 0.487 & 0.001 & 0.921 & -0.264 & 0.138 & -0.027 & 0.0192 \\
\hline Traffic & 0.049 & 0.281 & 0.021 & 0.254 & -0.096 & 0.050 & -0.164 & 0.000 \\
\hline Education & 0.033 & 0.000 & 0.004 & 0.625 & -0.062 & 0.221 & 0.141 & 0.0000 \\
\hline
\end{tabular}

In order to better study the factors affecting the efficiency of urban green development, the samples were grouped according to the radiation range of the aforementioned urban agglomerations and further regression (Table 5). From the perspective of the influence direction of the influencing factors, per capita GDP in Guanzhong Urban Agglomeration, Lanxi Urban Agglomeration, and Yanhuang Urban Agglomeration has the same influence as the full sample, but in Tianshanbeipo Urban Agglomeration, it has the opposite influence from all samples; the economic structure influences the urban agglomeration sample which is the same as the full sample; technological innovation is the same as the full sample in Lanxi urban agglomeration and Yanhuang urban agglomeration and opposite to the full sample in other urban agglomerations; the direction of population density in Lanxi urban agglomeration is the same as the full sample, and other urban agglomerations are the same as the full sample. On the contrary, the traffic situation in Guanzhong urban agglomeration and Lanxi urban agglomeration affects the same direction as the full sample, and other urban agglomerations are opposite to the full sample; education investment in Guanzhong urban agglomeration, Lanxi urban agglomeration, and Tianshanbeipo urban agglomeration affects the same direction as the full sample, and other city groups are the opposite of full sample. From the perspective of the significance of the influencing factors, technological innovation is significantly correlated in Lanxi urban agglomeration and Tianshanbeipo urban agglomeration; population density is significantly uncorrelated in Guanzhong urban agglomeration, Lanxi urban agglomeration, and Yanhuang urban agglomeration; traffic conditions are significantly uncorrelated in Guanzhong urban agglomeration and significantly unrelated in Lanxi urban agglomeration; education investment is significantly uncorrelated in Lanxi urban agglomeration and Yanhuang urban agglomeration.

\section{Conclusion}

The conclusions of this paper include the following three points. (1) Through the two-dimensional analysis of time and space, it is found that the overall urban green development in Northwest China is on a good trend, but there are great differences in the level of development between cities, and the unbalanced characteristics are prominent, and there is a path dependence and Matthew effect of "the strong is always strong, the weak is always weak." (2) In order to further study the core cities in Northwest China, it is proposed how to play a greater role in the efficiency of high green development. This paper analyzes the convergence and coordination of four urban agglomerations in Northwest China. It is found that there is no good linkage development model within the urban agglomerations, and their respective operations, resource redistribution, and other phenomena are obvious, which seriously hinder the spillover effect of urban agglomerations as regional growth poles. (3) To study the Northwest China, the driving factors of urban green development efficiency, combined with data characteristics, are analyzed by the Tobit model. It is found that economic development level, population density, traffic conditions, and education investment have significant positive impact on green development efficiency, industrial structure has significant negative impact on green development efficiency, and technological innovation has no significant impact. Based on the above analysis results, the following suggestions are put forward to promote the economic green development and high-quality development of cities in Northwest China.

5.1. Establish Scientific Concepts and Break Through Development Barriers Efficiently. The Northwest region is a concentrated area of traditional "high pollution and high energy consumption" industries in China. Therefore, to achieve a long-term green development mechanism, a scientific development concept must be established. First, the government must establish a green development concept and get rid of "pollution first and governance later." The traditional development path should avoid measuring regional development only by GDP and attach importance to the coordinated development of development quality and economic system-social system-ecosystem. Secondly, it is necessary to establish a scientific and green development evaluation system that meets the characteristics of regional development and promote cities to focus on a distinctive green development path. Finally, policy support should be given to guide the people to develop a green lifestyle, establish a green consumption concept, expand the green industry market, and increase the motivation for green development. This article measures the obstacles to the green development of regional cities. Therefore, under the guidance of scientific concepts, different regions should conduct scientific assessments of existing obstacles, formulate targeted policies, and break through development constraints 
in a reasonable and efficient manner. Formulate key industry development directions and economic policies based on the theory of comparative advantage, focus on breaking through the issue of green growth, and at the same time attach importance to social construction and reduce barriers to green welfare. Gansu Province, Qinghai Province, and Ningxia Autonomous Region will strengthen infrastructure construction and build more, while economic development in the Xinjiang Autonomous Region must maintain the development speed, optimize relevant policies, and improve the level of green development.

5.2. Improve Urban Green Synergy. It is found that there is a serious Matthew effect in the green development efficiency of cities in Northwest China. From the perspective of provincial level, the green development efficiency of Shaanxi Province is significantly higher than that of other four provinces. From the perspective of cities in the province, the green development efficiency of provincial capital cities is significantly higher than that of ordinary prefecture-level cities, and the spillover effect of better developed cities is not obvious. Therefore, it is necessary to improve the communication density between cities in Northwest China, and local governments must play a good role in policy guidance, promote cities with different green development efficiency to form mutual brother cities, and share the excellent experience in promoting the development of green industry, reducing pollutant emissions, accelerating the construction of green consumption market, and other aspects, so as to learn from each other and jointly promote green development. At the same time, the development of the northwest cannot be separated. To regard the northwest as the same economic area, each provincial government should set up a provincial development coordination platform, seek common ground while reserving differences, coordinate planning, and unify development, make full use of the natural resources and location advantages of the northwest, give full play to the coordination effect of node cities and important urban agglomerations, and expand the city of Guanzhong urban agglomeration led by Xi an. The opening degree of the city, including Longdong cities such as Qingyang and Tianshui into the overall planning of Guanzhong City Cluster, fully cooperates in green industry transfer and green technology sharing, and the provincial capitals along the Yellow River, led by Yinchuan and Lanzhou, should give full play to the influence of the provincial capitals and promote the green development of Zhongwei, Baiyin, and other intermediate cities through industrial coordination and resource sharing, Xining, as a city on the Qinghai-Tibet Plateau, should increase its ties with Lanzhou in terms of resource exchange, transportation, and make full use of the opportunity of Lanxi urban agglomeration to improve the quality of economic development. The northern slope urban agglomeration of Tianshan, led by Urumqi and Karamay, should not only actively integrate into the development groups of other northwest cities but also take the Northwest cities as the economic hinterland, actively connect with Central Asia Eastern European market, give full play to the location advantage of connecting Asian and European markets, improve the quality of development, and realize green development.

\subsection{Speeding up the Adjustment of Green Industry Structure.} In the study of this paper, the industrial structure factors have a significant negative impact on the green development of Northwest cities. In this paper, the proportion of the secondary industry is used to represent the industrial structure, so the growth of the secondary industry will inhibit the improvement of the green development efficiency. As the pillar industry in Northwest China, the secondary industry must speed up the pace of industrial structure adjustment. First of all, all provinces and cities must do a good job in top-level design according to their own industrial development, make full use of national think tank resources, give full play to the resource advantages of all regions to do a good job in policy guidance, and do a good job in the planning and key project preparation of industrial structure adjustment, so as to create a good platform for industrial structure adjustment; second, a backward area of China's economic development is the Northwest China's industry. In the process of structural adjustment, we should actively introduce advanced technology to the advantageous industries, realize industrial upgrading through technological transformation, promote the development of industries to low pollution, low energy consumption, and low emission, and constantly promote the growth of emerging industries. As a geothermal, solar, and wind energy rich area in China, Northwest China has energy advantages in big data, information, and other industries, so we should vigorously promote it. The implementation of relevant projects should actively introduce green high value-added industries and actively promote the development of ecological industries. Finally, a service-oriented government should be established to improve the administrative level of the government. Cities in Northwest China should pay more attention to the application of foreign capital, create a good environment for the entry of foreign capital, give full play to the leading role of foreign capital, and introduce excellent production management methods and technical level Different foreignfunded enterprises enter the northwest, give full play to the "catfish effect," and speed up the development of green industry through market competition.

\subsection{Introduce Human Capital and Accelerate Technological} Transformation. People are the foundation of development, but cities in Northwest China are facing the situation of low population concentration. Therefore, first of all, cities in Northwest China should introduce human capital, increase regional population density, attract people from counties, towns, and other areas to flow to cities, establish green channels in settlement policies, simplify settlement procedures, optimize settlement policies, and vigorously develop online application and approval The settlement system confirmed on the site will gather human capital; on this basis, we will vigorously introduce high-level talents, improve financial support, and introduce scientific research 
and management talents through preferential policies such as housing, spouse, and children's work, so as to provide talent support for green development. At the same time, we should also do a good job in retaining talents and improve the population's dependence on the city by providing suitable jobs, generous treatment level, good living environment, and full emotional care. In Xi'an, Lanzhou, and other provincial capitals with sufficient human capital, we should give full play to the advantages of talent gathering, accelerate the transformation of technological achievements, make use of the advantages of many colleges and universities and scientific research institutes, vigorously develop the economy of colleges and universities, promote the combination of production, teaching, and research, encourage teachers and researchers in colleges and universities to carry out research on technological transformation, build a joint platform for the transformation of scientific and technological achievements, fully connect the intellectual resources of scientific research institutes and production resources of enterprises, promote the transformation of scientific and technological achievements through platform development, establish funds for scientific and technological transformation, encourage enterprises to upgrade production technology, provide financial support, establish a good market system, improve the enthusiasm of enterprises to upgrade technology, and fully promote from two directions of technology theory and technology application transformation of scientific and technological achievements into industrial achievements.

\subsection{Strengthen Transportation and Education and Promote} Balanced Development. Transportation and education are two important measures to improve the efficiency of green development. Northwest China has complex terrain, poor natural conditions, and the overall traffic situation lags behind the national average. Meanwhile, the regional economic development is slow, the economic strength is weak, and it is difficult to improve the traffic conditions in an allround way objectively. Therefore, Northwest China must focus on the traffic construction and give full play to the market power, encourage private capital to enter the field of infrastructure construction, do a good job in road network planning, give priority to the construction of connecting roads between key counties and cities, and ensure the arterial connection of regional economy and, on this basis, carry out road construction sinking work, gradually connect counties and towns, and construct a road network for green economic development. Through this study, education investment will have a significant positive impact on the efficiency of green development. Therefore, it is an inevitable trend to continuously increase the investment in education to improve the efficiency of green development. The backward development of higher education in Northwest China is an important factor restricting the green development. Therefore, we should focus on increasing the investment in higher education. In the process of investment, we should make clear the key points, adopt the form of project application system to allocate funds, and combine the needs of regional industrial development, scientific research advantages, and environmental governance different scientific research projects should be set up to promote colleges and universities and research institutes to apply for special research on related topics, actively guide colleges and universities in other regions to participate in competition, stimulate academic vitality, link educational investment with scientific and technological development and transformation, and form a good cycle system.

\section{Data Availability}

The data used to support the findings of the study are available from the corresponding author upon request.

\section{Conflicts of Interest}

The authors declare that they have no conflicts of interset.

\section{References}

[1] A. G. Hu and S. J. Zhou, "Green development: functional definition mechanism analysis and development strategy," Chinese Journal China Population Resources and Environment, vol. 24, no. 1, pp. 14-20, 2014.

[2] Z. J. Feng, Y. H. Liu, Y. Jin, Q. Guo, and F. Yan, "Adhere to and improve the green road with Chinese characteristics," China Soft Science, vol. 9, pp. 1-7, 2015.

[3] W. J. Wang and D. Liu, "The evolution and practice of China's green development thought in the 70 Years since the founding of the people s Republic of China," Journal of Shaanxi Normal University (Philosophy and Social Sciences Edition), vol. 1, pp. 1-10, 2019.

[4] Z. Wei, Z. Mingyang, Z. Wenyao, Z. Qian, and Z. H. Xinxin, "What influences the effectiveness of green logistics policies? A grounded theory analysis," Science of the Total Environment, vol. 714, Article ID 136731, 2020.

[5] F. X. Lv, "Basic relations and models of green development: practices of Zhejiang merchants and suichang," Management World, vol. 11, pp. 166-169, 2013.

[6] K. Kunanuntakij, V. Varabuntoonvit, and N. Vorayos, "Thailand Green GDP assessment based on environmentally extended input-output model," Journal of Cleaner Production, vol. 167, no. 20, pp. 970-977, 2017.

[7] B. Panjapornpon, G. Egilmez, and R. Gedik, "Assessing the eco-efficiency of US manufacturing industries with a focus on renewable vs. non-renewable energy use: an integrated time series MRIO and DEA approach," Journal of Cleaner Production, vol. 253, pp. 119-130, 2020.

[8] I. L. Calzada, L. N. Maria, N. E. Ana et al., "Assessing the efficiency of sustainable cities using an empirical approach," Sustainability, vol. 12, no. 7, p. 2618, 2020.

[9] R. F. Yang and N. Li, "Environmental regulation and green industrial development of China: theoretical analysis and empirical evidence," Journal of China University of Geosciences (Social Sciences Edition), vol. 19, no. 5, pp. 79-91, 2019.

[10] Y. Gao, "Study on low-carbon and green development performance for countries along the Belt and road," Soft Science, vol. 33, no. 8, pp. 78-84, 2019.

[11] G. X. Zhang, W. Liu, and H. B. Duan, "Environmental regulation policies local government enforcement and pollution- 
intensive industry transfer in China," Computers \& Industrial Engineering, vol. 148, Article ID 106748, 2020.

[12] S. Z. Tian and Y. J. Ding, "Greenization measurement of urban agglomeration in Yangtze River Delta and its influence factors: an empirical study based on the entropy-tobit model of 26 cities panel data," Economic Geography, vol. 39, no. 9, pp. 94-103, 2019.

[13] X. Xu, J. Hao, L. Yu, and Y. Deng, "Fuzzy optimal allocation model for task-resource assignment problem in a collaborative logistics network," IEEE Transactions on Fuzzy Systems, vol. 27, no. 5, pp. 1112-1125, 2019.

[14] L. J. Si and H. Y. Cao, "The impact of emissions trading on pollution reduction:quasi-natural experimental analysis based on difference-in-differences model," Management Review, vol. 32, no. 12, pp. 15-26, 2020.

[15] B. Z. Zhu, M. F. Zhang, P. Wang, S. X. Ye, Z. H. Liu, and S. J. Yuan, "An empirical study on the influence of industrial structure adjustment on green development efficiency:a case study of guangxi," Social Sciences in Guangxi, vol. 8, pp. 50-56, 2019.

[16] X. F. Xu, Z. R. Lin, and J. Zhang, "DVRPLS with variable neighborhood region in refined oil distribution," Annals of Operations Research, vol. 9, pp. 1-25, 2020.

[17] L. J. Si, "Impact of environmental regulation on green technology innovation:empirical analysis based on panel data of the cities in Yellow River basin," Research on Financial and Economic Issues, vol. 7, pp. 41-49, 2020.

[18] M. J. Farrell, "The measurement of productive efficiency," Journal of the Royal Statistical Society. Series A (General), vol. 120, no. 3, pp. 253-290, 1957.

[19] R. W. Pittman, "Multilateral productivity comparisons with undesirable outputs," The Economic Journal, vol. 93, no. 372, pp. 883-891, 1983.

[20] L. Zhou, L. Che, and C. H. Zhou, "Spatio-temporal evolution and influencing factors of urban green development efficiency in China," Acta Geographica Sinica, vol. 10, pp. 1-18, 2019.

[21] X. F. Xu, J. Hao, and Y. Zheng, "Multi-objective artificial bee colony algorithm for multi-stage resource leveling problem in sharing logistics network," Computers \& Industrial Engineering, vol. 142, no. 4, Article ID 106338, 2020.

[22] B. Q. Lin and R. P. Tan, "Economic agglomeration and green economy efficiency in China," Economic Research Journal, vol. 54, no. 2, pp. 119-132, 2019.

[23] X. X. Li, Y. M. Liu, and T. Song, "Calculation of human green development index," Social Sciences in China, vol. 6, pp. 69-95+207, 2014.

[24] X. F. Xu, Z. F. Wei, Q. Ji, C. L. Wang, and G. W. Gao, "Global renewable energy development: influencing factors trend predictions and countermeasures," Resources Policy, vol. 63, no. 10, Article ID 101470, 2019.

[25] W. Chenxiao, Z. Qingpu, and Z. Wei, "Corporate social responsibility green supply chain management and firm performance: the moderating role of big-da2a analytics capability," Research in Transportation Business \& Management, vol. 37, no. 4, Article ID 100557, 2020.

[26] K. Tone, "A slacks-based measure of efficiency in data envelopment analysis," European Journal of Operational Research, vol. 130, no. 3, pp. 498-509, 2001.

[27] H. Fukuyama and W. L. Weber, "A directional slacks-based measure of technical inefficiency," Socio-Economic Planning Sciences, vol. 43, no. 4, pp. 274-287, 2009.

[28] Y. Gao, "Study on green development performance and influencing factors in eight comprehensive economic areas of
China," The Journal of Quantitative \& Technical Economics, vol. 36, no. 9, pp. 3-23, 2019.

[29] Y. J. Guo and Y. Zhao, "Spatial variation and relevant influence factors of green development levels among the counties in Ningxia," Economic Geography, vol. 35, no. 3, pp. $45-51+8,2015$.

[30] L. Huang and C. Q. Wu, "Industrial green development efficiency and spatial driven mechanism in cities of the Yangtze River economic belt," China Population Resources and Environment, vol. 29, no. 8, pp. 40-49, 2019. 